\title{
Efficacy of All-Trans-Retinoic Acid in High-Risk Acute Myeloid Leukemia with Overexpression of EVI1
}

\author{
Etienne Paubelle $\cdot$ Adriana Plesa $\cdot$ Sandrine Hayette $\cdot$ Mohamed Elhamri \\ Florence Zylbersztejn • Olivier Hermine · Gilles Salles • \\ Xavier Thomas
}

Received: January 9, 2019 / Published online: May 22, 2019

(C) The Author(s) 2019

\section{ABSTRACT}

Introduction: EVI1 (MECOM)-positive acute myeloid leukemia (AML) cells have shown in vitro sensitivity to all-trans-retinoic acid (ATRA) by inducing differentiation, cell death, and decreased leukemic engraftment.

Methods: In this pilot study, we investigated the response to ATRA in 13 high-risk AML patients with overexpression of EVI1.

Results: Seven of the 13 patients (53.8\%) achieved complete remission (CR), and response can be combined with a decreased of the leukemia stem cell pool.

Conclusion: These primary results tend to confirm in vitro results and suggest that

Enhanced Digital Features To view enhanced digital features for this article go to https://doi.org/10.6084/ m9.figshare.8011352.

E. Paubelle · M. Elhamri · G. Salles · X. Thomas $(\bowtie)$ Department of Clinical Hematology, Hospices Civils de Lyon, Centre Hospitalier Lyon-Sud, Pierre Bénite, France

e-mail: xavier.thomas@chu-lyon.fr

E. Paubelle

Faculté de Médecine Lyon-Sud Charles Mérieux, Université de Lyon, Pierre Bénite, France

E. Paubelle

Laboratoire de Biologie et Modélisation de la Cellule, CNRS UMR5239, Faculté de Médecine LyonSud, Ecole Normale supérieure de Lyon, Hospices Civils de Lyon, Pierre Bénite, France addition of ATRA might be of benefit in the treatment of patients with EVI1-positive AML.

Keywords: Acute myeloid leukemia; All-transretinoic acid; EVI1; Leukemia stem cells; MECOM

\section{INTRODUCTION}

Acute myeloid leukemia (AML) is the predominant acute leukemia among adults, characterized by an accumulation of malignant immature myeloid precursors. It represents a heterogeneous group of diseases with different responses to treatment, which can be separated by genetic abnormalities [1]. The MECOM locus in chromosome band 3q26.2 gives rise to two major mRNA and protein species, EVI1 and MDS1/EVI1, of which the former has been

\footnotetext{
A. Plesa $\cdot$ S. Hayette

Department of Biological Hematology, Hospices Civils de Lyon, Centre Hospitalier Lyon-Sud, Pierre-Bénite, France

F. Zylbersztejn · O. Hermine Laboratory of Molecular Mechanisms of Hematologic Disorders and Therapeutic Implications, Imagine Institute, Paris, France

O. Hermine

Department of Clinical Hematology, Hôpital

Necker-Enfants-Malades, Paris, France
} 
characterized for more extensively. The ecotropic viral integration site 1 (EVI1) gene is a proto-oncogene that encodes a zinc-finger DNA-binding protein previously detected in some AML and myelodysplastic syndromes (MDS) $[2,3]$, but not in normal marrow and cord blood cells. Enhanced expression of EVI1 is associated with a very poor disease outcome $[4,5]$, despite allogeneic hematopoietic stem cell transplantation [6]. Experimental studies suggest EVI1 blocks cellular differentiation by binding to GATA-1 or other specific DNA sequences controlling gene expression, and may be involved in the pathogenesis of some AMLs [7]. EVI1 influences transcription regulation in response to the myeloid differentiation inducing agent, all-trans-retinoic acid (ATRA) [8]. The EVI1 gene is consistently expressed in acute promyelocytic leukemia (APL) cells either constitutively or after ATRA therapy [9]. ATRA regulates EVI1 expression in blood cells [8].

ATRA is the paradigm of treatment in APL [10]. In addition to allowing transcriptomic activity downstream of retinoid receptor alpha $(R A R a)$, ATRA allows its degradation and acts on the pool of leukemic stem cells (LSCs) [11]. Because treatment of APL patients with ATRA is very successful, it has been hypothesize that ATRA might also be effective in treatment of other AML subtypes. Several clinical trials have already evaluated the combination of chemotherapy with ATRA in non-APL AMLs. Large randomized trials failed to observe an advantage to adding ATRA to induction chemotherapy [12-16]. Conversely, the ULM Study Group demonstrated an advantage to receiving ATRA with induction chemotherapy [17], and explorative subgroup analyses revealed better survival for genetic low-risk patients according to European LeukemiaNet (ELN) recommendations [18].

Several recent studies have shown that ATRA may efficiently drive leukemic cells into differentiation and/or apoptosis in a subset of AML patients with an NPM1 mutation [19], a FLT3ITD [20, 21], and/or an IDH-1 mutation [22]. Furthermore, it was recently demonstrated that enhanced expression of EVI1 in HL60 cells increased the response to ATRA, that the protein GDF15 is part of the ATRA-induced cell cycle block [8], and that the in vitro part of the EVI1-positive cases are sensitive to ATRA by inducing differentiation and cell death and decreasing leukemic engraftment [23].

Here, we retrospectively reviewed the response to ATRA of 13 high-risk AML patients with overexpression of EVI1. Our results showed that responses can be obtained and suggest that addition of ATRA to leukemia treatment might increase complete response (CR) rates or prevent relapses in EVI1-positive AML patients.

\section{METHODS}

Between February 2016 and January 2017, 13 consecutive patients with high-risk AML presenting EVI1 abnormalities were treated by ATRA. High-risk AML patients were defined either as AML patients in front-line therapy considered unfit for intensive chemotherapy, or as relapsed/refractory AML patients unfit for intensive treatment and/or who relapsed after allogeneic stem cell transplantation (ASCT) or after treatment for secondary AML. ATRA was given at $45 \mathrm{mg} / \mathrm{m}^{2} /$ day for two consecutive weeks each month and was administered initially either alone (3 patients) or combined with low-dose cytarabine $(20 \mathrm{mg} /$ day for 10 consecutive days with cycles of 28 days) (1 patient), azacitidine $\left(75 \mathrm{mg} / \mathrm{m}^{2} /\right.$ day for 7 consecutive days with cycles of 28 days) (4 patients), gemtuzumab ozogamicin $\left(3 \mathrm{mg} / \mathrm{m}^{2} /\right.$ day on days 1 , 4, and 7) (1 patient), or 6-mercaptopurine (50-100 mg/day) in association with low-dose methotrexate (10-15 mg/week) (4 patients), according to patient situation. Combination therapy was decided according to patient physical condition and patient past therapeutic history. Informed consent was obtained from all patients. The study was approved by the review board protocol of the Hospices Civils de Lyon and conducted in accordance with the Declaration of Helsinki.

Results for cytogenetic analysis were available in 12 patients and were classified according to the ELN recommendations [1]. RNA isolation and EVI1 real-time quantitative polymerase chain reaction (RQ-PCR) conditions for study of 
EVI1 overexpression were considered as previously recommended [4]. The 3q26 amplified cell line SKOV3 overexpressing EVI1 served as a calibrator for quantification. Only standard curves established by serial dilutions of SKOV3 cDNA aliquots with correlation coefficients larger than 0.9 were taken into account. Equal amplification efficiencies of target and reference genes in both EVI1 samples and SKOV3 at different cDNA concentrations were considered. The relative EVI1 expression was calculated using the delta-delta CT method. EVI1 expression levels were dichotomized based on a cut-off of 0.1 relative to SKOV3. In all patients, no other molecular abnormalities were detected among biological markers systematically investigated at the time of diagnosis or relapse (NPM1, FLT3-ITD, FLT3-TKD, IDH1/2).

Response to therapy was evaluated by bone marrow (BM) aspirates. In responding patients, cytological analysis was completed by minimal residual disease (MRD) monitoring using multiparametric flow cytometry immunophenotyping and/or molecular biology as previously described [24]. Descriptive statistics were used to characterize patients and their disease.

\section{RESULTS}

Patient characteristics at the time inclusion are reported in Table 1. Their outcomes are summarized in Table 2 . The median age was 65 years (range 49-81). Three of the 13 patients were newly diagnosed. All other patients had previously received one line ( 8 patients) or two lines of treatment including anthracycline plus cytarabine-based intensive chemotherapy (8 patients) eventually followed by ASCT (2 patients), or low-intensity therapy with cycles of hypomethylating agents ( 2 patients). Most of the patients presented with morphological signs of cytologic dysplasia, of which five had secondary AML. At the time of inclusion, Eastern Cooperative Oncology Group (ECOG) performance status (PS) was $\geq 2$ in six patients. Regarding cytogenetics, five patients displayed a normal karyotype, while seven had unfavorable-risk cytogenetics and one had cytogenetic failure.
Six patients did not achieve CR (Fig. 1a). Five (\#1, \#3, \#8, \#9, \#10) died within 5 months following treatment initiation (median 3 months; range $1-5)$. One (\#12) is still alive after 1.5 year with sequences of treatment (patient decision) using ATRA alone and then ATRA plus azacitidine. Among those six non-responding patients, three died before any evaluation could be performed, but three were evaluated for response: two patients (\#3 and \#12) showed decreased bone marrow blast infiltration after 5 months and 3 months of treatment, respectively, and one patient (\#1) showed a decreased peripheral blast percentage, from 63 to $18 \%$, after 1 month of therapy.

Seven patients achieved CR (Fig. 1b). Almost all of them had an initial low bone marrow leukemic burden (median 10\%; range 5-55\%). Patient \#2, who maintained for a while a low minimal residual disease (MRD) on ATRA plus gemtuzumab ozogamicin and then ATRA alone, achieved, after a frank relapse, a cytological CR with four cycles of ATRA plus azacitidine. Patient \#4 achieved CR after four cycles of ATRA plus low-dose cytarabine, while three patients (\#5, \#6, \#13) obtained CR after 2-6 cycles on ATRA plus azacitidine, and one patient (\#7) after 2 months on ATRA plus 6-mercaptopurine and methotrexate. Molecular remission was achieved in two patients (\#4, \#5) after treatment for 11 months and 6 months, respectively. At the time of analysis, four patients (\#6, \#7, \#11, \#13) had relapsed, two of which after stopping treatment because of major cutaneous rash (\#7) or by patient decision (\#13). Three patients (\#2, \#4, \#5) are still in continuous CR, although treatment was stopped in two of them.

Overall, treatment was well tolerated. Toxicity attributed to ATRA only included cutaneous rash (grade 3) in one patient (\#7) and cutaneous and mucosal dryness (grade 2) in another patient (\#2).

Multicolor/multidimensional flow cytometry was used to characterize the different leukemia compartments and evaluate the importance of the immature $\mathrm{CD} 34^{+} \mathrm{CD} 38^{-}$cell population compared to the more mature $\mathrm{CD} 34^{+} \mathrm{CD} 38^{\text {low }}$ and $\mathrm{CD} 34^{+} \mathrm{CD} 38^{+}$leukemic cell subpopulations. Although the LSC population is neither uniform nor static within individual 
Table 1 Patient characteristics at the time of inclusion

\begin{tabular}{|c|c|c|c|c|}
\hline Patient & $\begin{array}{l}\text { Age/sex/ } \\
\text { PS }\end{array}$ & AML subtype & Cytogenetics & Prior therapy \\
\hline$\# 1$ & $79 \mathrm{y} / \mathrm{F} / 2$ & $\begin{array}{l}\text { Undifferentiated with } \\
\text { myelofibrosis }\end{array}$ & Failure & None \\
\hline$\# 2$ & $67 \mathrm{y} / \mathrm{M} / 1$ & $\begin{array}{l}\text { AML-1 with multilineage } \\
\text { dysplasia }\end{array}$ & Normal & $\begin{array}{l}\text { 1st line: } \mathrm{IC}+\text { conso } \\
\text { 2nd line: } \mathrm{IC}+\mathrm{ASCT}\end{array}$ \\
\hline$\# 3$ & $52 \mathrm{y} / \mathrm{M} / 1$ & Secondary AML (NHL) & $\operatorname{Inv}(3),-7,+Y$ & 1st line: $\mathrm{IC}+$ conso \\
\hline$\# 4$ & $46 y / M / 1$ & AML-0 & Normal & 1st line: IC + salvage \\
\hline$\# 5$ & $48 \mathrm{y} / \mathrm{F} / 2$ & $\begin{array}{l}\text { Secondary AML (MDS) with } \\
\text { myelofibrosis }\end{array}$ & Failure & 1st line: IC + ASCT \\
\hline$\# 6$ & $60 \mathrm{y} / \mathrm{M} / 0$ & AML-0 & Normal & $\begin{array}{l}\text { 1st line: } \mathrm{IC}+\text { conso }+ \text { maint } \\
\text { (ATRA, } 6 \mathrm{MP}, \mathrm{MTX})\end{array}$ \\
\hline$\# 7$ & $73 y / M / 1$ & AML-2 & -7 & $\begin{array}{l}\text { 1st line: } \mathrm{LD}-\mathrm{AraC} \\
\text { 2nd line: anti-Bcl2 }\end{array}$ \\
\hline$\# 8$ & $65 \mathrm{y} / \mathrm{M} / 3$ & $\begin{array}{l}\text { Secondary AML (polycythemia } \\
\text { vera) }\end{array}$ & $\operatorname{Inv}(3), \operatorname{Abn} 12$ & 1st line: guadecitabine \\
\hline \#9 & $44 y / F / 2$ & Secondary AML & Complex & 1st line: $\mathrm{IC}+$ conso \\
\hline$\# 10$ & $81 \mathrm{y} / \mathrm{M} / 2$ & AML-5 & $\begin{array}{l}\operatorname{del}(3), \operatorname{del}(5), \operatorname{del}(7),-4 \\
\quad-11,-17\end{array}$ & None \\
\hline$\# 11$ & $70 \mathrm{y} / \mathrm{F} / 1$ & Secondary AML (CMML) & Normal & $\begin{array}{l}\text { 1st line: } \mathrm{IC}+\text { conso } \\
\text { (molecular relapse) }\end{array}$ \\
\hline \#12 & $62 \mathrm{y} / \mathrm{M} / 1$ & Secondary AML (MDS) & Normal & 1st line: azacitidine \\
\hline$\# 13$ & $68 \mathrm{y} / \mathrm{M} / 2$ & $\begin{array}{l}\text { Undifferentiated with atypical } \\
\text { mast cell component }\end{array}$ & $\operatorname{Inv}(3), 7 \mathrm{q}^{-}$ & None \\
\hline
\end{tabular}

6MP 6-mercaptopurine, $A M L$ acute myeloid leukemia, $A S C T$ allogeneic stem cell transplantation, $A T R A$ all-trans-retinoic acid, $C M M L$ chronic myelomonocytic leukemia, conso consolidations, $F$ female, $I C$ intensive chemotherapy, $L D$-Ara $C$ lowdose cytarabine, $N H L$ non-Hodgkin lymphoma, $M$ male, maint maintenance, $M D S$ myelodysplastic syndrome, $M T X$ methotrexate, $P t$ patient, $P S$ performance status, $y$ years

patients, the $\mathrm{CD}^{+} 4^{+} \mathrm{CD} 38^{-}$cell population, which certainly remains enriched in leukemia cells with self-renewal capacities, decreased significantly in patients responding to ATRA therapy (Fig. 2).

\section{DISCUSSION}

Enhanced expression of EVI1 (MECOM) occurs in approximately $10 \%$ of AML patients and is associated with a very poor disease outcome. Here we show that, despite treatments and patient heterogeneity, a substantial part of EVI1-positive AML patients can respond to ATRA therapy. These first clinical results tend to confirm the potential efficacy of ATRA-based therapy with an induction of differentiation and a significant reduction of survival previously described in leukemic cells from patients with EVI1 overexpression [23]. In mice models, ATRA treatment was also associated with less 
Table 2 Patient outcomes

\begin{tabular}{|c|c|c|c|}
\hline $\mathbf{P t}$ & Treatment & Response to therapy & OS \\
\hline$\# 1$ & $\mathrm{ATRA}+6 \mathrm{MP}+\mathrm{MTX}$ & No CR & 3 months \\
\hline \multirow[t]{3}{*}{$\# 2^{\mathrm{a}}$} & $\mathrm{ATRA}+\mathrm{GO}$ & $\downarrow \mathrm{MRD}$ & 30 months + \\
\hline & ATRA & No CR & \\
\hline & ATRA + azacitidine & CR with MRD-neg & \\
\hline$\# 3$ & ATRA + azacitidine & No CR & 6 months \\
\hline \multirow[t]{2}{*}{$\# 4^{\mathrm{b}}$} & ATRA + LD-AraC & $\mathrm{CR}$ & 27 months + \\
\hline & Then ATRA as maintenance & CR with MRD-neg & \\
\hline$\# 5$ & ATRA + azacitidine & CR with MRD-neg & 18 months + \\
\hline$\# 6$ & ATRA + azacitidine & CR with MRD-neg & 14 months + \\
\hline$\# 7$ & $\mathrm{ATRA}+6 \mathrm{MP}+\mathrm{MTX}$ & CR & 17 months \\
\hline$\# 8$ & $\mathrm{ATRA}+6 \mathrm{MP}+\mathrm{MTX}$ & No CR & 1 month \\
\hline$\# 9$ & ATRA & No CR & 3 months \\
\hline$\# 10$ & $\mathrm{ATRA}+6 \mathrm{MP}+\mathrm{MTX}$ & No CR & 1 month \\
\hline \multirow[t]{2}{*}{$\# 11^{\mathrm{c}}$} & ATRA & $\mathrm{CR}$ & 22 months + \\
\hline & ATRA + azacitidine & CR & \\
\hline \multirow[t]{2}{*}{$\# 12^{\mathrm{d}}$} & ATRA & No CR & 18 months + \\
\hline & ATRA + azacitidine & No CR & \\
\hline \multirow[t]{2}{*}{$\# 13^{\mathrm{e}}$} & ATRA + azacitidine & CR & 12 months \\
\hline & ATRA + azacitidine & No CR & \\
\hline
\end{tabular}

6-MP 6-mercaptopurine, ATRA all-trans-retinoic acid, $C R$ complete remission, $G O$ gemtuzumab ozogamicin, LD-AraC low-dose cytarabine, $M R D$ minimal residual disease, $M R D$-neg MRD-negative, $M T X$ methotrexate, $O S$ overall survival

a Patient \#2 received a combination of ATRA with GO followed by ATRA alone $\left(45 \mathrm{mg} / \mathrm{m}^{2} /\right.$ day for two consecutive weeks each month), while in morphological CR, because of persistence of MRD positivity. MRD (determined by flow cytometry) significantly decreased after 2 months of treatment. ATRA alone was resumed 6 months later after MRD increased again, followed by treatment with combination ATRA plus azacitidine after morphological relapse. This combination allowed CR achievement after four cycles then molecular remission after 13 cycles

b Patient \#4 achieved morphological CR with the ATRA plus LD-AraC combination. He then received ATRA alone $\left(45 \mathrm{mg} / \mathrm{m}^{2} /\right.$ day for two consecutive weeks each month) as maintenance therapy and achieved molecular remission (determined by flow cytometry)

${ }^{c}$ Patient \#11 achieved morphological remission after 3 months of treatment with ATRA alone. After relapse, she received ATRA plus azacitidine and achieved a new morphological CR after four cycles

d Patient \#12 failed to achieve response with ATRA alone and then after combining ATRA with azacitidine

' Patient \#13 achieved morphological CR after two cycles of ATRA plus azacitidine then decided to stop the treatment. After relapse, the combination ATRA plus azacitidine did not allow CR achievement

leukemic engraftment suggesting a decreased clonogenic capacity with a direct effect of ATRA on LSCs overexpressing EVI1 [23]. EVI1 is able to modulate the ATRA response of several genes, and has been shown to reinforce the ATRA response in the majority of AML cases [8]. In the present study, we showed that ATRA alone or combined with various other treatments could 


\section{(A)}

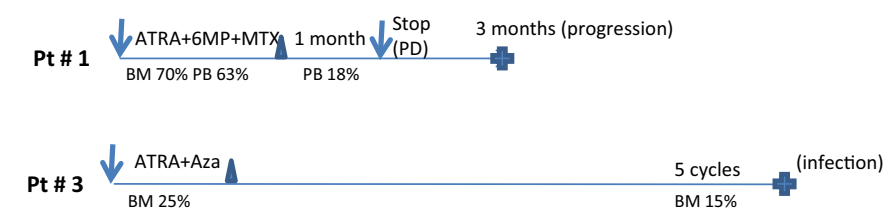

Pt \# $8 \frac{\swarrow_{\text {BM } 40 \%}^{\text {ATRA+6MP+MTX }} 1 \text { month (infection) }}{3}$

Pt \# $9 \frac{\downarrow \text { ATRA }}{\text { BM } 40 \%}$

Pt \# $10 \frac{\downarrow \text { ATRA+6MP+MTX }}{\text { BM } 80 \%} 1$ month (infection)

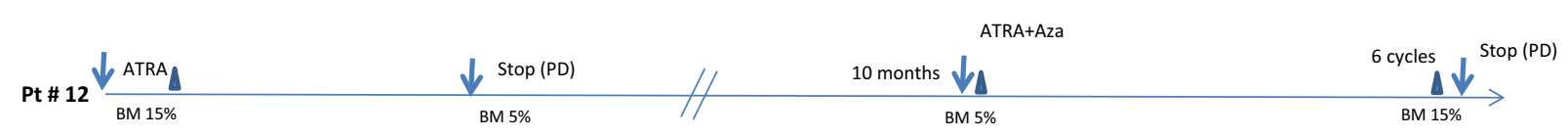

(B)

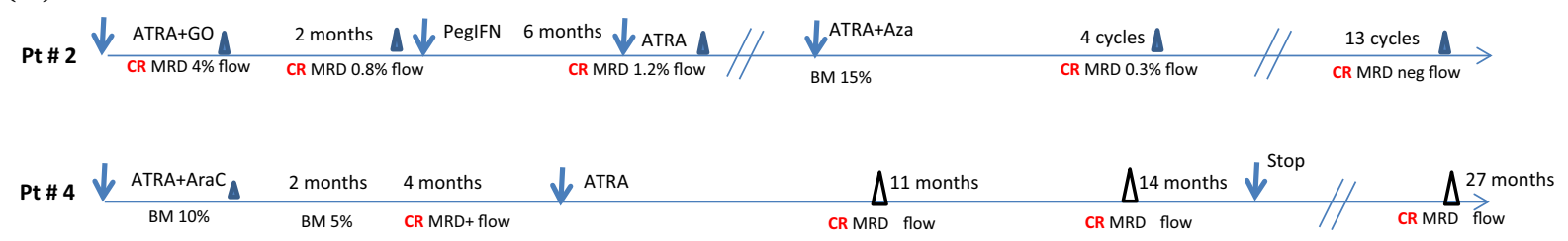

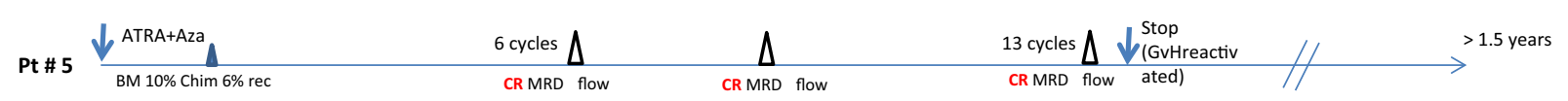

\begin{tabular}{|c|c|c|c|c|}
\hline & ATRA+Aza & 6 cycles & 10 cycles $\downarrow$ & $\begin{array}{l}\text { Stop (Intensive } \\
\text { chemo) }\end{array}$ \\
\hline & BM $10 \%$ & CR MRD $1.2 \%$ flow & BM 15\% & \\
\hline
\end{tabular}

Pt \# $7 \underset{\text { BM } 55 \%}{\downarrow \text { CR MRD flow 6\% }} \begin{array}{ll}\text { ATRA+6MP+ } \\ \text { MTX }\end{array}$

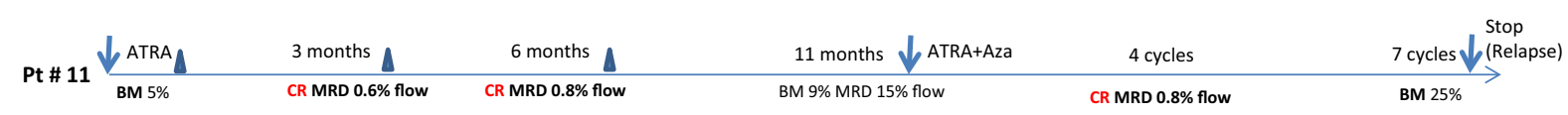

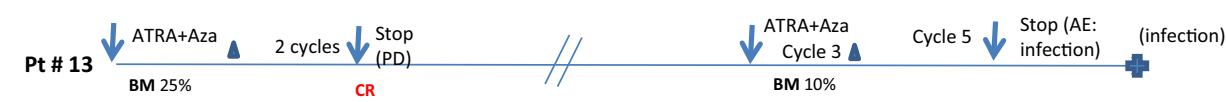
- EVI-1 positive
$\triangle \quad$ EVI-1negative
I Death 
4Fig. 1 Evolution on ATRA therapy in patients who did not achieve CR (a) and in patients who achieved CR (b). 6MP 6-mercaptopurine, AE adverse event, AraC low-dose cytarabine, $A T R A$ all-trans-retinoic acid, $A z a$ azacitidine, $B M$ bone marrow, chemo chemotherapy, Chim chimerism, $C R$ morphological complete remission, flow flow cytometry, $G O$ gemtuzumab ozogamicin, $G v H$ graft-versus-host reaction, $M R D$ minimal residual disease, $M T X$ methotrexate, neg negative, PegIFN peginterferon, $P B$ peripheral blood, $P D$ patient decision, $P t$ patient

have a beneficial effect in AML patients with overexpression of EVI1. CR and even molecular remission were obtained in patients with unfavorable prognostic factors (age, comorbidities, unfavorable cytogenetics, prior therapeutic lines). All patients were considered high-risk and primary unfit for intensive chemotherapy or secondary unfit after having received one or two lines of intensive or low-intensity therapy. These complete responses were mainly obtained in patients with a low leukemic burden. Only one patient with initially more than $50 \%$ of bone marrow blasts achieved CR. However, most of responses were short. This could be likely attributed to a suboptimal therapy, poor treatment compliance in a generally frail patient population and/or to a lost treatment efficacy after repeated treatment administrations. Overexpression of EVI1 is associated with a poor prognosis in AML probably due to its important role in the maintenance of LSCs [25]. Because of their quiescent state LSCs are not targeted by any antimitotic chemotherapy, and are at the origin of relapses conferring a poor outcome [26]. Targeting LSCs remains a main challenge in the treatment of AML. In APL, the association of ATRA with arsenic trioxide has demonstrated an LSC pool exhaustion [27] and is thereby able to cure most of the patients [28]. In our study, multiparameter flow cytometry analysis tended to show a diminution of the

\section{(A)}
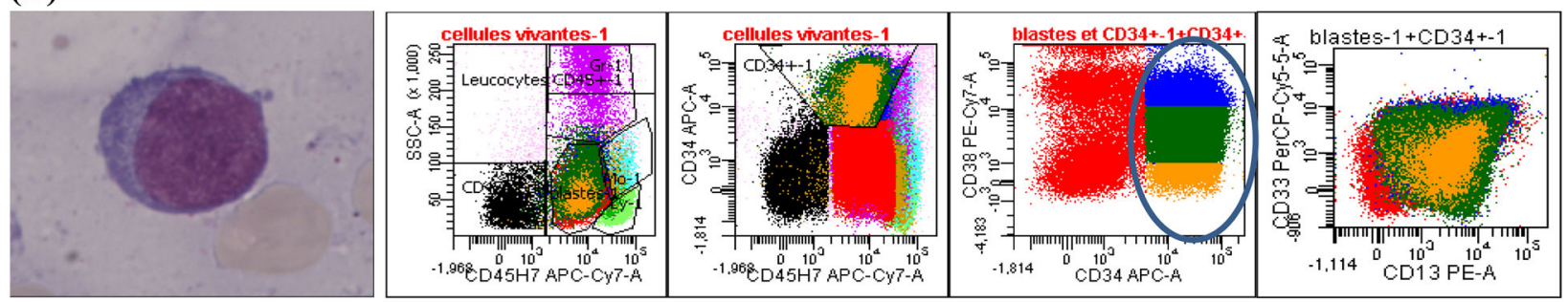

(B)
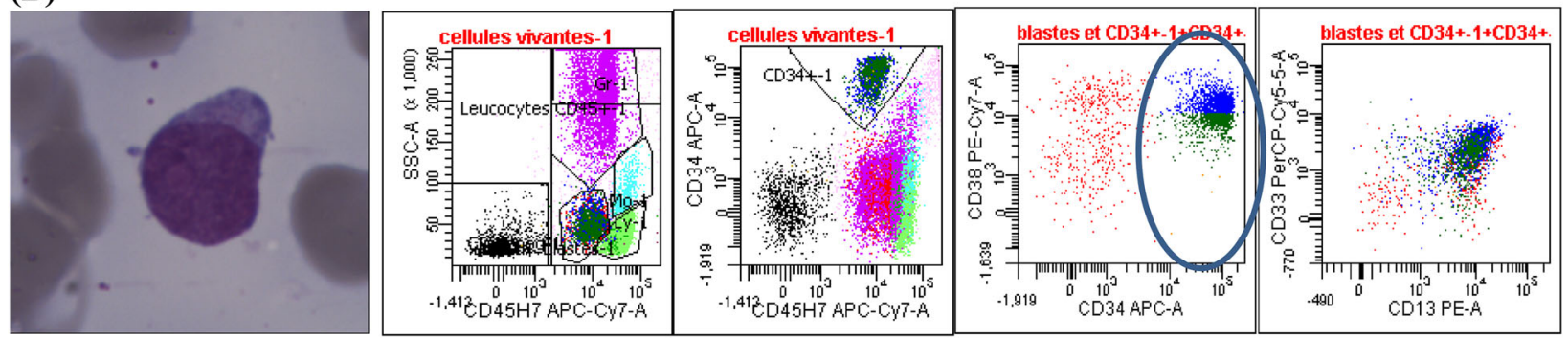

Fig. 2 Strategy used for gating the blast cell population and $\mathrm{CD} 34^{+} \mathrm{CD} 38$ cell subpopulations [red: immature CD $45^{\text {low }} / \mathrm{SSC}$ blast cells; blue: $\mathrm{CD} 34^{+}$cells, green: lymphocytes, blue cyan: monocytes, violet: granulocytes, black: $\mathrm{CD} 45^{+}$cells (erythroblasts)]; CD34 ${ }^{+}$cells were then separated into different stem cell fractions based on their CD38 antigen expression: a first cell population expressing a large amount of the CD34 antigen and lack of $\mathrm{CD} 38\left(\mathrm{CD} 34^{+} \mathrm{CD} 38^{-}\right)$(yellow), a second cell population characterized by a large amount of $\mathrm{CD} 34$ antigen and by a low density of $\mathrm{CD} 38$ antigen $\left(\mathrm{CD} 34^{+} \mathrm{CD} 38^{\text {low }}\right)$ (green), and a third cell population characterized by a high density of $\mathrm{CD} 38$ antigen and of CD34 antigen $\left(\mathrm{CD} 34^{+} \mathrm{CD} 38^{+}\right)$ (blue). Blast cell morphology and immunostaining in patient \#7 before ATRA introduction (55\% of bone marrow blasts) (a), and after 2 months of ATRA therapy $(<5 \%$ blasts on bone marrow smears and MRD at 6\% detected by flow cytometry) (b) 
LSC pool, indicating that ATRA might act by targeting LSCs. Although no morphological cell differentiation was observed under ATRA therapy, response to therapy was accompanied in immunostaining by a massive expression of CD38, which is known as a regulator of induced cell differentiation and growth arrest [29]. However, complementary treatment strategies are required to improve ATRA responsiveness in EVI1-positive AML. Recently, a combined effect of ATRA and bromodomain inhibitor JQ1 has been demonstrated on non-APL AML cells with a synergistic growth inhibition resulting from differentiation or apoptosis [30]. Similarly, inhibition of the SUMO pathway appeared as a promising strategy to sensitize patients with non-APL AML to retinoids [31], and the combination of ATRA with the anti-CD38 daratumumab to increase cytotoxicity among AML blasts in vitro and overall survival in murine engraftment models of AML [32]. Preliminary studies have suggested that the epigenetic and transcriptional state of leukemia cells determines their susceptibility to ATRA [33]. LSCs are in a different epigenetic state than the total bulk of the AML. Inhibitors of epigenetic-modifying enzymes might sensitize AML cells to ATRA therapy by driving these LSCs to maturity [34]. Hypermethylation of the promoter RAR $\alpha$ is common in AML and causes a decrease in its expression [35]. EVI1-positive AML patients have been shown with a distinct methylation profile [36] and downregulation of EVI1 results in epigenetic alterations [37]. Therefore, the association of ATRA and demethylating agents seems logical and could be synergistic in the AML with overexpression of EVI1.

Although promising, results of our retrospective study should be interpreted with caution. There are first several important limitations mainly due to the small number of patients and the heterogeneity of combination therapies. Secondly, some drugs used in combination with ATRA have previously been shown to be effective in controlling AML for variable periods of time, even in high-risk patients, and their potential relative contribution to transitory favorable results cannot be firmly eliminated.

\section{CONCLUSIONS}

Although our study showed important limitations, it brings major information confirming in humans a prior in vitro study that demonstrated a potential effect of ATRA in AML displaying EVI1 abnormalities [23]. Combination treatments may likely up-regulate ATRA activity resulting in increased overall survival. In this setting, we are currently testing this approach in a phase 3 randomized study comparing ATRA plus azacitidine versus azacitidine alone in AML patients with EVI1 overexpression unfit for intensive chemotherapy. Combination of ATRA with ' $3+7$ ' chemotherapy could also be proposed for patients with EVI1 overexpression considered fit for intensive treatment.

\section{ACKNOWLEDGEMENTS}

We thank the participants of the study.

Funding. No funding or sponsorship was received for this study or publication of this article.

Authorship. All named authors meet the International Committee of Medical Journal Editors (ICMJE) criteria for authorship for this article, take responsibility for the integrity of the work as a whole, and have given their approval for this version to be published.

Authorship Contributions. EP designed the study, included patients, analyzed and interpreted data, and wrote the manuscript; XT designed the study, included patients, analyzed data, and reviewed the manuscript; AP was responsible for coordinating immunophenotyping data; ME collected the data and provided technical support; $\mathrm{SH}$ was responsible for coordinating molecular biology; $\mathrm{OH}$ included patients; GS and FZ participated in data discussion and reviewed the manuscript.

Disclosures. The authors (EP, XT, AP, ME, $\mathrm{SH}, \mathrm{OH}, \mathrm{GS}, \mathrm{FZ}$ ) have nothing to disclose and declare no competing financial interests. 
Compliance with Ethics Guidelines. All procedures performed in the study were in accordance with the review board protocol of the Hospices Civils de Lyon and with the 1964 Helsinki declaration and its later amendments. Informed consent was obtained from all individual participants included in the study.

Data Availability. The data sets generated and/or analyzed during the current study are available from the corresponding author on reasonable request.

Open Access. This article is distributed under the terms of the Creative Commons Attribution-NonCommercial 4.0 International License (http://creativecommons.org/licenses/ by-nc/4.0/), which permits any noncommercial use, distribution, and reproduction in any medium, provided you give appropriate credit to the original author(s) and the source, provide a link to the Creative Commons license, and indicate if changes were made.

\section{REFERENCES}

1. Döhner H, Estey E, Grimwade D, et al. Diagnosis and management of AML in adults: 2017 ELN recommendations from an international expert panel. Blood. 2017;129:424-47.

2. Lugthart S, Groschel S, Beverloo HB, et al. Clinical, molecular, and prognostic significance of WHO type $\operatorname{inv}(3)(\mathrm{q} 21 \mathrm{q} 26.2) / \mathrm{t}(3 ; 3)(\mathrm{q} 21 ; \mathrm{q} 26.2)$ and various other $3 \mathrm{q}$ abnormalities in acute myeloid leukemia. J Clin Oncol. 2010;28:3890-8.

3. Hinai AA, Valk PJ. Aberrant EVI1 expression in acute myeloid leukaemia. $\mathrm{Br} \mathrm{J}$ Haematol. 2016;172:870-8.

4. Groschel S, Lugthart S, Schlenk RF, et al. High EVI1 expression predicts outcome in younger adult patients with acute myeloid leukemia and is associated with distinct cytogenetic abnormalities. J Clin Oncol. 2010;28:2101-7.

5. Barjesteh WDKS, Erpelinck C, van Putten WL, et al. High EVI1 expression predicts poor survival in acute myeloid leukemia: a study of 319 de novo AML patients. Blood. 2003;101:837-45.

6. He X, Wang Q, Cen J, et al. Predictive value of high EVI1 expression in AML patients undergoing myeloablative allogeneic hematopoietic stem cell transplantation in first CR. Bone Marrow Transpl. 2016;51:921-7.

7. Laricchia-Rabbio L, Fazzina R, Li D, et al. Point mutations in two EVI1 Zn fingers abolish EVI1GATA1 interaction and allow erythroid differentiation of murine bone marrow cells. Mol Cell Biol. 2006;26:7658-66.

8. Steinmetz B, Hackl H, Slabakova E, et al. The oncogene EVI1 enhances transcriptional and biological responses of human myeloid cells to alltrans retinoic acid. Cell Cycle. 2014;13:2931-43.

9. Xi ZF, Russell M, Woodward S, et al. Expression of the $\mathrm{Zn}$ finger gene, EVI-1, in acute promyelocytic leukemia. Leukemia. 1997;11:212-20.

10. Castaigne S, Chomienne C, Daniel MT, et al. Alltrans retinoic acid as a differentiation therapy for acute promyelocytic leukemia. I. Clinical results. Blood. 1990;76:1704-9.

11. Ablain J, Leiva M, Peres L, Fonsart J, Anthony E, de The $\mathrm{H}$. Uncoupling RARA transcriptional activation and degradation clarifies the bases for APL response to therapies. J Exp Med. 2013;210:647-53.

12. Belhabri A, Thomas X, Wattel E, et al. All-trans retinoic acid in combination with intermediatedose cytarabine and idarubicin in patients with relapsed or refractory non promyelocytic acute myeloid leukemia: a phase II randomized trial. Hematol J. 2002;3:49-55.

13. Milligan DW, Wheatley K, Littlewood T, et al. Fludarabine and cytosine are less effective than standard ADE chemotherapy in high-risk acute myeloid leukemia, and addition of G-CSF and ATRA are not beneficial: results of the MRC AML-HR randomized trial. Blood. 2006;107:4614-22.

14. Burnett AK, Milligan D, Prentice AG, et al. A comparison of low-dose cytarabine and hydroxyurea with or without all-trans retinoic acid for acute myeloid leukemia and high-risk myelodysplastic syndrome in patients not considered fit for intensive treatment. Cancer. 2007;109:1114-24.

15. Burnett AK, Hills RK, Milligan DW, et al. Attempts to optimize induction and consolidation treatment in acute myeloid leukemia: results of the MRC AML12 trial. J Clin Oncol. 2010;28:586-95.

16. Estey EH, Thall PF, Pierce S, et al. Randomized phase II study of fludarabine + cytosine arabinoside + idarubicin \pm all-trans retinoic acid \pm granulocyte colony-stimulating factor in poor prognosis newly diagnosed acute myeloid leukemia and myelodysplastic syndrome. Blood. 1999;93:2478-84. 
17. Schlenk RF, Frohling S, Hartmann F, et al. Phase III study of all-trans retinoic acid in previously untreated patients 61 years or older with acute myeloid leukemia. Leukemia. 2004;18:1798-803.

18. Schlenk RF, Lübbert M, Benner A, et al. All-trans retinoic acid as adjunct to intensive treatment in younger adult patients with acute myeloid leukemia: results of the randomized AMLSG 07-04 study. Ann Hematol. 2016;95:1931-42.

19. Martelli MP, Gionfriddo I, Mezzasoma F, et al. Arsenic trioxide and all-trans retinoic acid target NPM1 mutant oncoprotein levels and induce apoptosis in NPM1-mutated AML cells. Blood. 2015;125:3455-65.

20. Wang LN, Tang YL, Zhang YC, et al. Arsenic trioxide and all-trans-retinoic acid selectively exert synergistic cytotoxicity against FLT3-ITD AML cells via co-inhibition of FLT3 signaling pathways. Leuk Lymphoma. 2017;58:2426-38.

21. Ma HS, Greenblatt SM, Shirley CM, et al. All-trans retinoic acid synergizes with FLT3 inhibition to eliminate FLT3/ITD + leukemia stem cells in vitro and in vivo. Blood. 2016;127:2867-78.

22. Boutzen $\mathrm{H}$, Saland $\mathrm{E}$, Larrue $\mathrm{C}$, et al. Isocitrate dehydrogenase 1 mutations prime the all-trans retinoic acid myeloid differentiation pathway in acute myeloid leukemia. J Exp Med. 2016;213:483-97.

23. Verhagen HJMP, Smit MA, Rutten A, et al. Primary acute myeloid leukemia cells with overexpression of EVI-1 are sensitive to all-trans retinoic acid. Blood. 2016;127:458-63.

24. Plesa A, Dumontet C, Mattei E, et al. High frequency of $\mathrm{CD}^{+} 4^{+} \mathrm{CD} 38^{-}$/low immature leukemia cells is correlated with unfavorable prognosis in acute myeloid leukemia. World J Stem Cells. 2017;9:227-34.

25. Goyama S, Yamamoto G, Shimabe M, et al. Evi-1 is a critical regulator for hematopoietic stem cells and transformed leukemic cells. Cell Stem Cell. 2008;3:207-20.

26. Gentles AJ, Plevritis SK, Majeti R, Alizadeh AA. Association of a leukemic stem cell gene expression signature with clinical outcomes in acute myeloid leukemia. JAMA. 2010;304:2706-15.
27. Nasr R, Guillemin MC, Ferhi O, et al. Eradication of acute promyelocytic leukemia-initiating cells through PML-RARA degradation. Nat Med. $2008 ; 14: 1333-42$.

28. Lo-Coco F, Avvisati G, Vignetti M, et al. Retinoic acid and arsenic trioxide for acute promyelocytic leukemia. N Engl J Med. 2013;369:111-21.

29. Lamkin TJ, Chin V, Varvayanis S, et al. Retinoic acid-induced CD38 expression in HL-60 myeloblastic leukemia cells regulates cell differentiation or viability depending on expression levels. J Cell Biochem. 2006;97:1328-38.

30. Kang C, Kim CY, Kim HS, Park SP, Chung HM. The bromodomain inhibitor JQ1 enhances the responses to all-trans retinoic acid in HL-60 and MV4-11 leukemia cells. Int J Stem Cells. 2018;11:131-40.

31. Baik H, Boulanger $M$, Hosseini $M$, et al. Targeting the SUMO pathway primes all-trans retinoic acidinduced differentiation of non promyelocytic acute myeloid leukemias. Cancer Res. 2018;78:2601-13.

32. Buteyn NJ, Fatehchand K, Santhanam R, et al. Antileukemic effects of all-trans retinoic acid in combination with daratumumab in acute myeloid leukemia. Int Immunol. 2018;30:375-83.

33. Schenk T, Chen WC, Göllner S, et al. Inhibition of the LSD1 (KDM1A) demethylase reactivates the alltrans-retinoic acid differentiation pathway in acute myeloid leukemia. Nat Med. 2012;18:605-11.

34. Van Gils N, Verhagen HJMP, Smit L. Reprogramming acute myeloid leukemia into sensitivity for retinoic-acid-driven differentiation. Exp Hematol. 2017;52:12-23.

35. Chim CS, Wong SY, Pang A, et al. Aberrant promoter methylation of the retinoic acid receptor alpha gene in acute promyelocytic leukemia. Leukemia. 2005;19:2241-6.

36. Lugthart S, Figueroa ME, Bindels E, et al. Aberrant DNA hypermethylation signature in acute myeloid leukemia directed by EVI1. Blood. 2011;117:234-41.

37. Vazquez I, Maicas M, Cervera J, et al. Down-regulation of EVI1 is associated with epigenetic alterations and good prognosis in patients with acute myeloid leukemia. Haematologica. 2011;96:1448-56. 